\title{
Singularidades do envelhecimento: reflexões com base em conversas com um idoso institucionalizado
}

Lilian Juana Levenbach de Gamburgo ${ }^{1}$ Maria Inês Bacellar Monteiro

GAMBURGO, L.J.L.; MONTEIRO, M.I.B. Singularities of aging: reflections from conversations with an institutionalized elderly person. Interface - Comunic., Saúde, Educ., v.13, n.28, p.31-41, jan./mar. 2009.

This paper deals with some peculiarities of the life of an elderly person living in a long-stay institution, interviewed within a study context in which investigating the language (considered as dialogic practice) of elderly people whose communication skills remained intact was the aim. The narrative allowed us to find out about living conditions and some specific features such as: (1) early institutionalization; (2) the interdependence between the reasons for voluntary institutionalization and the situation regarding abandonment; and (3) the apparent impropriety of using the term "elderly" to include individuals with very different ages. Five women and one man were interviewed. These interviews enabled examination of memories, feelings, values, interpersonal relations and the language itself. We hope to provide support for looking at elderly people's communication such that it is considered to be a fundamental symbolic system for social inclusion, instead of centering on changes considered "typical" of old age.

Key words: Aging. Language. Institutionalization.
Este artigo trata de algumas peculiaridades da vida de um idoso que mora numa Instituição de Longa Permanência, entrevistado no contexto de uma pesquisa cujo objetivo foi a linguagem como prática dialógica de idosos com as capacidades comunicativas preservadas. A narrativa nos permitiu conhecer as condições de vida e algumas especificidades tais como: (1) a institucionalização precoce; (2) a interdependência entre os motivos para o asilamento voluntário e a situação de abandono; (3) a aparente impropriedade de utilizar a categoria "idosos" para englobar sujeitos com idades muito diversas. Foram entrevistados cinco mulheres e um homem. As entrevistas propiciaram o exame de lembranças, sentimentos, valores, relações interpessoais e da própria linguagem. Esperamos oferecer subsídios para um olhar sobre a comunicação do idoso que a considera como sistema simbólico fundamental para a inserção social, olhar diverso daquele centrado nas alterações consideradas "típicas" da velhice.

Palavras-chave: Envelhecimento. Linguagem. Institucionalização.
${ }^{1}$ Fonoaudióloga. Universidade Metodista de Piracicaba. Rua 14 de dezembro, 504, apto. 81. Campinas, SP, Brasil. 13.015-130 gamburgo@mpc.com.br

2 Fonoaudióloga. Programa de PósGraduação em Educação, Universidade Metodista de Piracicaba. 


\section{Introdução}

Este artigo tem por objetivo refletir a respeito de algumas singularidades relativas ao envelhecimento e à institucionalização de idosos no Brasil, identificadas com base na realização de um estudo intitulado Envelhecimento e linguagem: um estudo da linguagem como prática dialógica e social em idosos ${ }^{3}$. A pesquisa objetivou a linguagem de homens e mulheres que estão em processo de envelhecimento e que conservam as capacidades comunicativas preservadas. Ao mesmo tempo em que construímos novos conhecimentos, buscamos apreender o modo como cada indivíduo via a si mesmo e a sua própria linguagem. Com esse propósito, foram utilizados os relatos da memória afetiva e da história de vida de seis idosos. Por meio de entrevistas não estruturadas, os participantes recuperaram e reexaminaram suas lembranças, sentimentos, valores, opiniões, e as relações interpessoais estabelecidas ao longo da vida, considerando que: cada indivíduo é um ser da linguagem, sendo esta constitutiva e fundamental para o seu desenvolvimento como sujeito; a linguagem está vinculada de modo inseparável ao homem singular, que faz uso dela para interagir e comunicar-se; e cada indivíduo é produto do conjunto das relações sociais que o cercam.

Ao mesmo tempo em que os sujeitos puderam falar de si, voltaram-se para a sua linguagem e as oportunidades de diálogo, num exercício de reflexividade, pois: "[...] o homem fala de si, (re)conhece-se, volta-se sobre si mesmo pela linguagem, a qual pode falar de seu próprio acontecimento" (Smolka, 1995, p.41).

Os participantes tinham idades entre 61 e 81 anos. Quatro eram solteiros (um homem e três mulheres) e moravam numa Instituição de Longa Permanência para idosos (ILPI). Os outros (duas mulheres viúvas) moravam em suas próprias residências. Todos assinaram o correspondente Termo de Consentimento Livre e Esclarecido. As entrevistas foram individuais, realizadas pela mesma investigadora, gravadas e transcritas. Começaram com perguntas semiestruturadas destinadas a traçar o perfil socioeducacional, e continuaram com a proposição de que cada um falasse sobre sua família, infância, escolaridade, relações sociais, de trabalho, opiniões etc. Os dados foram objeto de uma análise qualitativa, e organizados em torno dos seguintes eixos temáticos, formulados em função dos temas abordados ao longo dos diálogos: Família e vida afetiva; Esferas sociais, culturais e de trabalho; Sentimentos, crenças e valores pessoais; Opinião sobre a própria linguagem; Memórias; Vida na Instituição. Por não ser o objetivo desta pesquisa estabelecer um diálogo entre áreas distintas de conhecimento (Garnelo, 2006), não foi realizada triangulação com outras técnicas ou métodos qualitativos

As informações originadas nas entrevistas permitiram-nos constatar um dos aspectos mais consensuais no que se refere aos idosos, a saber: que o envelhecimento é um fenômeno essencialmente heterogêneo. Bassit o expressa com as seguintes palavras:

[...] envelhecer é uma experiência única para cada indivíduo, diversificada entre pessoas de um mesmo grupo social e heterogênea tanto entre indivíduos como em diferentes grupos sociais [...] o processo de envelhecimento, em função de sua múltipla determinação, implica diversidade, individualidade e variabilidade entre os indivíduos. (Bassit, 2004, p.143)

Neste texto destacamos a situação peculiar de Irineu (nome fictício). Desejamos, por meio dele, focalizar as múltiplas possibilidades oferecidas pela linguagem como sistema simbólico para que o sujeito estabeleça contato com os

\author{
${ }^{3}$ Dissertação de \\ Mestrado, aprovada pelo \\ Comitê de Etica, \\ defendida em dezembro \\ de 2006, pela primeira \\ autora, dentro do \\ Programa de Pós- \\ Graduação em Educação \\ da Universidade \\ Metodista de Piracicaba, \\ com orientação da \\ segunda autora.
}


bens culturais; e dar subsídios para direcionar a maneira de olhar a linguagem do idoso, afastando-nos da visão centrada na detecção de alterações e patologias "típicas" da velhice.

Partimos de uma concepção baseada em Mikhail Bakhtin (1895-1975), para quem a linguagem sempre é dialógica e discursiva e tem caráter interativo, histórico, cultural e social (Brait, Mello, 2005). Afirmamos que a linguagem é um componente essencial para a inserção social, para a saúde geral e uma vida com qualidade e autonomia na velhice. A despeito do declínio biológico característico, o homem e a mulher conservam possibilidades de transformação, desenvolvimento e mudança, devidas à plasticidade do funcionamento cognitivo e social.

Bakhtin ressalta o papel central da dimensão semiótica no processo de constituição do sujeito, que ocorre ao longo de toda a vida, somente cessando com a chegada da morte. As funções superiores, tipicamente humanas (memória, linguagem, pensamento, formação de conceitos etc.), são relações sociais internalizadas, mediadas pelo signo - a linguagem - que estabelece a comunicação (Vigotski, 1995). Graças à plasticidade do cérebro, a linguagem organiza essas funções, e, para isso, é fundamental a interação socialdiscursiva. Por meio da linguagem somos capazes de expressar nossas idéias, pensamentos e sentimentos; e de transmitir as experiências e os conhecimentos adquiridos através dos tempos, nos diversos contextos sociais em que se desenvolvem as nossas atividades, notadamente as interações com familiares, amigos e colegas. Assim, a linguagem é essencial para a continuidade da inserção social do sujeito em processo de envelhecimento.

Sendo atividade constitutiva e meio de comunicação e expressão, a linguagem também é instrumento de recuperação, reflexão e compreensão da memória construída socialmente, inscrita nas narrativas da história de vida de cada um. Isto significa dizer que a linguagem também é meio de constituição da memória, da subjetividade e da intersubjetividade nas experiências partilhadas, como é afirmado por Smolka (2000, p.187-8): “[...] a linguagem não é apenas instrumental na (re)construção das lembranças; ela é constitutiva da memória, em suas possibilidades e seus limites, em seus múltiplos sentidos, e é fundamental na construção da história". Nessas experiências nos apropriamos dos valores e conceitos ideológicos que transitam nesse momento histórico e nesse lugar social, pois " [...] a constituição da subjetividade é marcada pelas condições de produção (materiais e ideológicas) nas quais cada pessoa se insere" (Kassar, 2000, p.45).

\section{A entrevista com Irineu}

Para este texto, escolhemos recortes de entrevistas com Irineu, dentre as seis realizadas para a pesquisa. Esta escolha se justifica pela singularidade de sua situação, conforme veremos a seguir. Não é nossa intenção contrastar a fala de Irineu com as dos outros sujeitos, nem considerá-la paradigmática em nenhum sentido. Queremos chamar a atenção para o fato de Irineu poder ser visto como representativo de uma grande parcela de idosos institucionalizados e precocemente dependentes: sujeitos solteiros, viúvos e/ou alijados/abandonados pela família, que vão morar numa ILPI para obter a assistência necessária que lhes permita viver os últimos anos de suas vidas.

Irineu tinha 61 anos, mas aparentava ser mais velho. Era solteiro e não tinha filhos. Relatou ter nascido e trabalhado, por muito tempo, num sítio que ficava próximo da ILPI, e ter completado o "primário" (atual Ensino Fundamental). Sua profissão era pintor residencial. A sua família de origem era composta pelos pais e quatro irmãos. Ao tempo da entrevista, não tinha contato com nenhum familiar e compartia um quarto coletivo em um dos pavilhões para pessoas carentes. Residia na instituição havia quatro anos (desde os 57 anos), por não poder mais trabalhar, já que apresentava sequelas de um acidente de trânsito que deixara seu braço direito inabilitado, e também por falta de outras opções onde morar. A ajuda da assistente social havia sido decisiva para a internação (isto fica evidenciado em um trecho que apresentamos da entrevista).

Viver em uma Instituição de Longa Permanência é um direito estabelecido pela Política Nacional do Idoso (Decreto n.1.948, de 1996), que entende, por modalidade asilar, o atendimento - em regime de internato - ao idoso sem vínculo familiar ou sem condições de prover as suas necessidades de moradia, alimentação, saúde e convivência social (Brasil, 1996).

Também a Lei n.10.741, de outubro de 2003, que dispõe sobre o Estatuto do Idoso, estabelece 
que "O idoso tem direito a moradia digna, no seio da família natural ou substituta, ou desacompanhado de seus familiares, quando assim o desejar, ou, ainda, em instituição pública ou privada" (Brasil, 2003). Será prestada a modalidade de entidade de longa permanência quando se verifique abandono, inexistência de grupo familiar, ou carência de recursos financeiros. E as instituições " [...] são obrigadas a manter padrões de habitação compatíveis com as necessidades deles, bem como provê-los com alimentação regular e higiene [...]" 4 .

As instituições asilares devem proporcionar serviços nas áreas: social, médica, psicológica, odontológica, de enfermagem, fisioterapia, terapia ocupacional, entre outras, de acordo com as necessidades deste segmento etário (Born, 2005). No Brasil, assim como nos demais países em desenvolvimento, é considerado idoso todo indivíduo a partir da chegada aos sessenta anos de idade ${ }^{5}$. Nos países desenvolvidos, é estabelecida a chegada à velhice aos 65 anos. Esta variação é devida a fatores de ordem biológica, cultural, ambiental e econômica, entre outros.

Born (2004a) afirma que é impossível pretender ignorar o fato de que o envelhecimento da população brasileira acontece num ritmo acelerado e num ambiente de grandes transformações sociais, entre as quais se sobressaem: a participação crescente da mulher no mercado de trabalho e os novos arranjos familiares - muitas vezes constituídos por mães solteiras, casais sem filhos, pessoas cujos filhos emigram etc. Assim, a perspectiva de envelhecer num ambiente familiar ou de a mulher vir a exercer o papel de cuidadora dos parentes idosos fica sensivelmente reduzida, embora o Estatuto do Idoso disponha que é obrigação da família, da comunidade e da sociedade - além do Poder Público - assegurar ao idoso que seja respeitado e efetivado " [...] o direito à vida, à saúde, à alimentação, à educação, à cultura, ao esporte, ao lazer, ao trabalho, à cidadania, à liberdade, à dignidade, ao respeito e à convivência familiar e comunitária".

Ao priorizar o atendimento familiar em detrimento do asilar, as diretrizes do Estatuto do Idoso e da Política Nacional do Idoso não consideraram nem as mudanças na estrutura familiar mencionadas acima, nem o aumento do número de idosos dependentes e com necessidade de cuidados especiais, segundo atesta a Carta aberta de Santos (2007), elaborada no Fórum Estadual das ILPI, no marco do V Congresso Paulista de Geriatria e Gerontologia, GERP (2007), que descreve a ocorrência de uma

[...] mudança no perfil de idosos institucionalizados ocorrida nos últimos anos, isto é, de pobreza e falta de rede familiar para a predominância de idosos com incapacidade e dependência física e/ou cognitiva, morbidades crônicas não transmissíveis e a falta de acesso a serviços de saúde através de convênios/planos de saúde.

Assim, a internação numa ILPI pode obedecer a causas de ordem individual, social, econômica, de saúde, ou a uma combinação das mesmas. Algumas das causas sociais são: solidão e abandono, carência ou desintegração da família, falta de uma rede social de suporte, impossibilidade de a família continuar proporcionando cuidados. E, dentre as dificuldades de ordem econômica, as mais frequentes são: necessidades decorrentes de problemas de saúde ou dependência, diminuição do poder aquisitivo, impossibilidade de pagar por serviços, de manter a moradia ou de aceder a uma alimentação minimamente adequada.

Após responder algumas questões referentes a aspectos socioeducacionais, assim como os demais entrevistados, Irineu foi convidado a narrar livremente a respeito de: sua história de vida, da sua família, profissão, relacionamentos sociais
${ }^{4}$ Disponível em: <http:/ /www.direitodoidoso. com. br >. Acesso em: 7 jan. 2009.

${ }^{5}$ A definição de idoso englobando as pessoas maiores de sessenta anos foi estabelecida pela Lei n.8842, de 4 de janeiro de 1994, e regulamentada pelo Decreto n. 1948, de 3 de julho de 1996, que dispõe sobre a política nacional do idoso. Disponível em: <http:// www.ripsa.org.br/ fichasIDB/record.php? node $=$ A.14\&lang $=p t>$. Acesso em: 7 jan. 2009 
etc. A história de Irineu nos permitiu tomar ciência de suas condições de vida, e, também, perceber algumas situações que ocorrem com certa frequência nas ILPI. Sua entrevista trouxe à tona características que valem a pena conhecer quando o tema dos idosos institucionalizados entra em cena, e sobre as quais tecemos algumas considerações. Estas temáticas se apresentam, a nosso ver, como constituintes de uma dada situação dentro do quadro da institucionalização:

- A idade do velho: a institucionalização precoce e as diferenças de idade dentro da categoria dos idosos.

. Asilamento e abandono.

\section{A idade do velho: a institucionalização precoce e as diferenças de idade dentro da categoria dos idosos}

No seu caráter de coordenadora nacional do Fórum de ILPI e de participante da V Caravana Nacional de Direitos Humanos - realizada em 2002 -, Tomiko Born refere ter conhecido grande número de instituições em todo o país. Ela verificou que a população das instituições é muito heterogênea em idade e em condições de saúde, nelas podendo ser encontradas pessoas com diversas patologias e deficiências, tais como: deficiência visual, auditiva, mental, psicóticos com diagnósticos variados, e pessoas com diversos quadros demenciais (Born, 2004b).

A autora registra também a ocorrência da institucionalização precoce, bastante frequente, em que pessoas com idade inferior aos sessenta anos encontram-se nas instituições asilares por carecerem de família ou por terem sequelas de Acidente Vascular Cerebral ou suspeita de algum processo demencial em fase inicial (Ortiz, Bertolucci, 2005), e que necessitam de cuidados ou simplesmente de um lugar para viver.

Ainda há poucos dados que ilustrem esta situação. Com base na pesquisa que é realizada desde 2006 pelo Instituto de Pesquisa Econômica Aplicada (IPEA), em cinco regiões brasileiras, com a finalidade de elaborar um retrato do funcionamento das

A pesquisa, iniciada em 2006, intitulada Condições de

funcionamento e de infraestrutura nas instituições de longa permanência para idosos no Brasil, foi realizada pelo Ipea, em parceria com a

Secretaria Especial dos Direitos Humanos (SEDH) da Presidência da República e o Conselho Nacional dos Direitos do Idoso (CNDI). Disponível em: <http:// www.ipea.gov.br/ default.jsp $>$. Acesso em: 7 jan. 2009
Instituições de Longa Permanência e das condições de vida dos idosos que nelas residem ${ }^{6}$, hoje se sabe que há, aproximadamente, cem mil idosos morando em seis mil ILPI espalhadas por todo o país. No entanto o número de moradores com menos de sessenta anos é desconhecido, podendo chegar a ser expressivo, segundo Born, atingindo, em alguns casos, cerca de $40 \%$ do total de internos. Eles são acolhidos por se encontrarem em situação de fragilidade social, às vezes vivendo sós na comunidade, ou sofrendo de doença física e/ou mental que os coloca em situação de dependência e consequente perda da autonomia.

Uma tentativa de explicação deste fenômeno poderia ser que, até pouco tempo atrás, o Programa do Idoso da Secretaria de Assistência e Desenvolvimento Social do Estado permitia a internação de pessoas a partir dos cinquenta anos, que sofressem de alguma forma de exclusão social ou que fossem consideradas precocemente envelhecidas (Born, 2006). Irineu tinha 61 anos à época da nossa entrevista, havendo ingressado na ILPI com 57 anos. Assim, ele pode ser incluído no perfil descrito acima, ou seja, o de uma pessoa com mais de cinquenta anos, com características de exclusão social, e que foi precocemente institucionalizada.

Entre os idosos entrevistados, Irineu era o mais jovem (tinha 61), existindo uma diferença de vinte anos entre ele e o entrevistado mais velho, de 81 anos. Isto representa quase uma geração. O exemplo de Irineu mostra uma realidade multifacetada, que é própria da história do envelhecimento populacional que ocorre no Brasil: (a) todo indivíduo é considerado idoso a partir dos sessenta anos; (b) o contingente de idosos, na sociedade, cresce a um ritmo muito acelerado; e (c) esta categoria, por sua vez, está envelhecendo devido ao aumento da longevidade, não 
somente no Brasil, mas no mundo todo. Hoje se sabe que, para um número crescente de pessoas, é possível superar os noventa, cem anos de vida, situação comum em países como Alemanha, Itália, França e Japão. Assim, uma consequência disto é a coexistência de pessoas de sessenta, setenta, oitenta, noventa anos ou mais nos contextos sociais, todas englobadas na grande categoria dos que chegaram à velhice.

Então, o que é a velhice? O que é ser idoso? Citando um trecho do livro País jovem com cabelos brancos (Veras, 1995), Minayo e Coimbra afirmam que "Velhice é um termo impreciso [...] nada flutua mais do que os limites da velhice em termos de complexidade fisiológica, psicológica e social" (Minayo, Coimbra, 2002, p.14). O envelhecimento pressupõe a ocorrência de modificações em vários níveis. As mudanças ocorrem para todos, mas em momentos e intensidades diferentes, e dependem de características genéticas, ambientais e sociais. O envelhecimento é, portanto, um híbrido biológico-social. A velhice, assim como a infância, a adolescência ou a vida adulta, não é uma propriedade que os indivíduos adquirem.

Pelo contrário: o processo biológico, que é real e pode ser reconhecido por sinais externos do corpo, é apropriado e elaborado simbolicamente por meio de rituais que definem, nas fronteiras etárias, um sentido político e organizador do sistema social [...] essas fronteiras e suas apropriações simbólicas não são iguais em todas as sociedades nem na mesma sociedade, em momentos históricos diferenciados - nem num mesmo tempo, para todas as classes, todos os segmentos e gêneros. (Minayo, Coimbra, 2002, p.15)

Assim, não existe uma resposta única à pergunta sobre "ser idoso", já que a heterogeneidade é a característica mais marcante da velhice. Dois sujeitos com a mesma idade poderão apresentar características muito diferentes em um ou vários aspectos de seu modo de ser e estar no mundo: uma pessoa de sessenta anos pode identificar-se e ser identificada como idosa por reconhecer, em si, aspectos compatíveis com as de uma pessoa de mais idade. Este foi o caso de Irineu, que disse considerar-se e sentir-se velho aos 61 anos, como pode ser verificado em seu discurso:

L. [...] na vida do senhor agora daqui pra frente o que que o senhor considera qualidade de vida?

I. Viver os dia-a-dia o melhor possível, porque pelo contrario o que que a gente tem? Esperança o que que é? Eu acho que não há mais tempo pra nada.

L. O senhor acha que não há mais tempo pra nada agora?

I. Não, pra dizer uma esperança assim, ter um futuro melhor, eu acho que não há porque num... a gente próprio num tem consistência pra isso, então a gente sugere que... o término da vida já ta meio (escrita) ${ }^{7}$... por causa da idade, da velhice.

L. O senhor se sente velho?

I. Olha, eu sinto sim idoso.

L. Se sente idoso?

I. É velho, velho, velho por completo ainda não.

L. Que diferença o senhor vê entre idoso e velho?

I. Eu vejo com que a pessoa ta mais próximo ao fim da vida né, isso daí a gente vê, isso daí é hereditário à todos nós, é o caso de vida

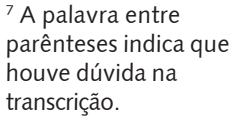

A palavra entre parênteses indica que houve dúvida na transcrição. 
nossa, e veja tem pessoas que vive um dia tem outras pessoas que vive cem anos ou então ou até mais de cem anos... as vezes é isso daí. L. E o que que o senhor espera pra sua vida daqui pra frente? I. O que que eu espero? Eu espero uma dádiva de Deus, uma benção que dê um futuro assim, bem melhor pra gente, meu procedimento de vida é esse.

\section{Asilamento e abandono}

Com relação a este tema, observa-se, com frequência, que é possível encontrar uma correlação entre os motivos que levaram uma pessoa a morar numa ILPI e o abandono. Em uma pesquisa com trinta sujeitos (dez institucionalizados e vinte que moravam em seus domicílios), cujo objetivo foi conhecer o que os idosos entendiam por abandono na velhice e quais circunstâncias podem provocálo, Herédia, Cortelletti e Casara (2005), afirmaram que

A partir das falas dos idosos entrevistados, entendeu-se que abandono na velhice é um sentimento de tristeza e de solidão, provocado por circunstâncias relativas a perdas, as quais se refletem basicamente em deficiências funcionais do organismo e na fragilidade das relações afetivas e sociais, que por sua vez conduzem a um distanciamento, podendo culminar no isolamento social.

Sofrer perdas constitui uma situação muito frequente na velhice: além da perda de familiares e amigos, a aposentadoria ou outras causas que levem à saída do mercado de trabalho, provocam a perda de status, da consideração dos outros e, muitas vezes, da possibilidade de se autossustentar financeiramente. Por meio da narrativa de Irineu, soubemos que, devido ao acidente de trânsito - uma perda importante na sua vida - ele precisou deixar de trabalhar, sendo esse um dos motivos que levaram ao seu asilamento. No recorte que se segue, Irineu relata a respeito do acidente:

${ }^{8}[\ldots]$ Trechos excluídos dos enunciados.

${ }^{9}(())$ Comentários da pesquisadora.
L. $[\ldots]^{8}$ E como é que foi o acidente $[\ldots]$ ?

I. Esse acidente do braço aqui, este daqui foi a gente vindo do trabalho, foi num cruzamento de avenida com rua assim.

L. O senhor tava aonde?

I. Na garupa da moto.

L. Ah, era a moto do senhor?

I. Não, do amigo, amigo de serviço ((tosse) $)^{9}$, a gente tinha toda razão, isso ai a gente sabe disso, farol aberto pá nós e o carro entra na frente, o cruzamento é numa subida e a gente dá uma meia puxadinha na aceleração e bateu forte, a gente teve até a felicidade de num ser mais prejudicado.

L. O senhor tinha me dito naquela ocasião que a cabeça não bateu não né, Graças a Deus.

I. Não, a cabeça não, (só braço), foi só a matéria do braço a raspage, assim da carne isso aí é normal, eu tive essa felicidade.

L. E fico no hospital muito tempo?

I. A fiquei sim, fiquei nove dias.

L. Nove dias, e fizeram gesso no senhor, como é que foi? Por que fico prejudicado o movimento?

I. Porque isso aqui geralmente foi erro médico. 


\author{
L. Ah é? \\ I. Só posso cita pa senhora isso ai [...] a gente passou pelo Pronto Socorro num médico que \\ dava assistência em matéria de troca de gesso, matéria assim de tirar nova radiografia, uma \\ coisa ou outra, [...] ele falou, até geralmente tem sigilo entre eles, a gente também não vai \\ cita nome do médico, porque o médico que me fez este serviço, ele praticamente foi criado \\ perto da minha casa, e a gente se conhece, ele é muito falado, ele é muito bom ortopedista, \\ mas infelizmente acontece, que erro é humano, não vamo condenar ninguém, então eu \\ deixei pra lá, vou faze o que eu não vou prejudica o médico, não vou prejudica a ((nome do \\ hospital)), não vou prejudica nada. \\ L. Que idade o senhor tinha quando foi esse acidente? \\ I. A esse daqui também foi em noventa e três, esse acidente. \\ L. [...] O senhor tava trabalhando na época? \\ I. Sim, eu vinha vindo do serviço. \\ L. E que aconteceu com o trabalho do senhor depois disso? \\ I. Que aconteceu? Que a gente trabalhava ambulante por conta, foi obrigatório parar.
}

Nos enunciados que reproduzimos a seguir, fica ilustrada a situação e a percepção de solidão e abandono em que Irineu vivia após ter deixado de trabalhar, assim como sua decisão e as circunstâncias que rodearam a sua institucionalização.

I. Tem uma senhora aqui [...] ela fez a proposta pra mim, ela tava por dentro da minha vida do jeito que eu vivia... né [...] Eu analisei bem por mim, falei: ué, não é bicho de sete cabeça né, vamos lá ver [...] Mas tinha o pobrema de idade naquela época.[...] Porque eu fui roubado, nesta época que eu fiquei sozinho na minha vida, documentação minha não tinha nada [...] então nós marcamos um encontro em frente aquele ((nome do lugar))...

[...] Bom eu fui lá como eu conheço tudo [...] conversamos lá, [a assistente social] fez milhões de pergunta pra mim, falei tudo bem, aí eu citei tudo os pormenores né, eu não sou mentiroso, eu sou realista, isso eu só [...] Ce bebe muito? Falei não, bebo socialmente acho como quarquer pessoa bebe socialmente [...] ce não tem documentação? Falei não. Falou, que dia que cê nasceu? Falei dia vinte e nove do quatro de quarenta e três é a minha data de nascimento... Então ela analisou bem, falou, ma cê não tem sessenta ano, falei: é muito simples se é que senhora teja vontade de eu ta permanente lá, vamos fazer o seguinte, antecipar se da pra senhora antecipar. Mas como? Falei a data de nascimento em vez de ser quarenta e três quarenta né que daí daria os sessenta ...

\title{
Considerações finais
}

No nosso estudo a respeito da linguagem no processo de envelhecimento, pudemos testemunhar como os idosos, enquanto fazem uso da sua linguagem, significam e avaliam sua vida, sua inserção na família, no trabalho, na cultura e nas atividades sociais; refletem sobre suas oportunidades (ou falta) de diálogo, e se desdobram tomando a si mesmos como objetos de atenção e análise. Irineu teve a oportunidade de recuperar e reexaminar suas lembranças, seus sentimentos, valores e as relações interpessoais estabelecidas ao longo da vida. A partir dos encontros foi possível observar, conhecer e interagir com um sujeito pensando e falando sobre suas experiências.

Numa conversa preliminar verificamos que Irineu se comunicava verbalmente sem dificuldades aparentes. Ao longo da entrevista, de aproximadamente três horas de duração, constatamos tratar-se de uma pessoa ávida por contato, disponível e bem disposta para o diálogo, mostrando-se à vontade, como se estivesse desfrutando da oportunidade e da "platéia". Foi minucioso na sua narrativa, não perdendo o intuito discursivo, mesmo durante os longos circunlóquios e numerosas informações e detalhes 
${ }^{10}$ Informações disponíveis em: < http:// www.ecodebate.com.br/ 2008/09/25/ibgesintese-dos-indicadoressociais-2007-uma-analisedas-condicoes-de-vida-dapopulacao-brasileira/ $>$. Acesso em: 7 jan. 2009. referentes a lugares, pessoas, datas e circunstâncias. Tampouco se furtou a falar de suas impressões e opiniões relativas a pessoas de seu convívio e à instituição.

Os diálogos nos levaram a tomar ciência dos desejos, opiniões e angústias de um indivíduo que, ao precisar se afastar do mercado de trabalho e ser institucionalizado, foi perdendo paulatinamente as oportunidades de convívio social e o direito de ter e usar sua própria voz.

Como pudemos perceber, a história de Irineu permitiu que nos aproximássemos de alguns aspectos importantes, surgidos ao colocarmos o foco da nossa investigação em idosos morando em uma ILPI, a saber: (1) a institucionalização precoce, que acontece antes de o sujeito chegar aos sessenta anos, idade determinada como início da velhice no Brasil; (2) a interdependência entre os motivos para o asilamento voluntário e uma situação que pode ser caracterizada como abandono (isto é, a falta de amparo e assistência e um lugar para morar); (3) a aparente impropriedade de se utilizar a categoria "idoso" para englobar sujeitos com idades muito distantes, como aconteceu na nossa pesquisa.

Antes de finalizar, é importante relembrar que nossa sociedade experimenta um acelerado processo de envelhecimento populacional. Dados do Instituto Brasileiro de Geografia e Estatística (IBGE) mostraram que, em 2007, os idosos representavam $10,5 \%$ da população total (quase vinte milhões) ${ }^{10}$. Este processo de transição demográfica, ao mesmo tempo coloca em evidência grandes conquistas na área médico-sanitária, e uma realidade permeada por desigualdades sociais crônicas existentes no Brasil.

À luz desta situação, recorremos novamente à Carta Aberta de Santos (2007), para alertar que a maioria das Instituições de Longa Permanência enfrenta dificuldades para continuar prestando cuidados a pessoas que, em sua maioria, se encontram em situação de fragilidade física e social. Apesar das garantias previstas pelo Estatuto do Idoso, “ [...] o Estado Brasileiro não oferece as devidas condições para a sua efetivação, as políticas públicas existentes não contemplam integralmente as necessidades das pessoas idosas". É, portanto, urgente uma tomada de consciência sobre as necessidades que as ILPI enfrentam para suprir as exigências de moradia e cuidados com a saúde física e mental dos idosos que são por elas acolhidos.

\section{Colaboradores}

As autoras Lilian Juana Levenbach de Gamburgo e Maria Inês Bacellar Monteiro participaram igualmente na elaboração e discussão do artigo. Lilian J. L. de Gamburgo realizou a revisão bibliográfica e a revisão final do texto. 


\section{Referências}

BASSIT, A.Z. Na condição de mulher: a maturidade feminina. In: PY, L. et al. (Orgs.). Tempo de envelhecer: percursos e dimensões psicossociais. Rio de Janeiro: Nau, 2004. p.137-57.

BORN, T. Carros de bois e ILPI - a propósito da tarefa de elaborar uma nova legislação. 2006. Portal do envelhecimento. Disponível em: <http:// www.portaldoenvelhecimento.net/artigos/artigo1033.htm>. Acesso em: 7 jan. 2009.

O que é uma Instituição de Longa Permanência? Rio de Janeiro, 2005. Disponível em: <http://chagas.redefiocruz.fiocruz.br/ ensp/biblioteca/dados/ tomiko.ppt>. Acesso em: 7 jan. 2008.

Conselho Nacional dos Direitos do Idoso - CNDI. Considerações sobre os asilos no Brasil. 2004a.. Disponível em: <http://www.mj.gov.br/sedh/ct/cndi/ consideracoes.htm>. Acesso em: 7 jan. 2009.

Asilo de idosos: a estação final de uma trajetória marcada por indignidades! 2004b. Portal do envelhecimento. Disponível em: <http:// www.portaldoenvelhecimento.net/acervo/retratos/retratos1.htm>. Acesso em: 7 jan. 2009.

BRAIT, B.; MELO, R. Enunciado/enunciado concreto/enunciação. In: BRAIT, B. (Org.). Bakhtin: conceitos-chave. São Paulo: Contexto, 2005. p.61-78.

BRASIL. Presidência da República. Subchefia para Assuntos Jurídicos. Lei n. 10.741, de $1^{\circ}$. de outubro de 2003. Disponível em: <http://www.planalto.gov.br/ccivil_03/LEIS/ 2003/L10.741.htm >. Acesso em: 7 jan. 2009.

. Presidência da República. Subchefia para Assuntos Jurídicos. Decreto n.1.948, de 3 de julho de 1996. Disponível em: <http://www.planalto.gov.br/CCIVIL/decreto/ D1948.htm>. Acesso em: 7 jan. 2009.

CARTA aberta de Santos. Fórum das Instituições de Longa Permanência para Idosos. Espaço Tomiko Born. 2007. Disponível em <http://www.portaldoenvelhecimento.net/ artigos/artigo2553.htm>. Acesso em: 7 jan. 2009.

GARNELO, L. Avaliação por triangulação de métodos: abordagem de programas sociais. Cad. Saude Publica, v.22, n.5, p.1115-8, 2006. Disponível em: <http:// www.scielo.br/pdf/csp/v22n5/25.pdf>. Acesso em: 7 jan. 2009.

HERÉDIA, V.; CORTELLETTI, I.; CASARA, M. Abandono na velhice. Textos

Envelhecimento, v.8, n.3, p.1-11, 2005. Disponível em: <http://www.unati.uerj.br/ tse/scielo.php?script $=$ sci_arttext $\&$ pid $=\$ 1517-59282005000300002 \& \operatorname{lng}=$ pt \&nrm =iso >. Acesso em: 7 jan. 2009.

KASSAR, M. Marcas da história social no discurso de um sujeito: uma contribuição para a discussão a respeito da constituição social da pessoa com deficiência. Cad. Cedes, v.20, n.50, p.41-54, 2000.

MINAYO, M.C.; COIMBRA, C.E. Entre a liberdade e a dependência: reflexões sobre o fenômeno social do envelhecimento. In: MINAYO, M.C. (Org.). Antropologia, saúde e envelhecimento. Rio de Janeiro: Fiocruz, 2002. p.11-24.

ORTIZ, K.Z.; BERTOLUCCI, P.H.F. Alterações de linguagem nas fases iniciais da doença de Alzheimer. Arq. Neuro-Psiquiatr., v.63, n.2-A, p.311-7, 2005. Disponível em: <http://www.scielo.br/pdf/anp/v63n2a/a20v632a.pdf>. Acesso em: 7 jan. 2009.

SMOLKA, A.L.B. A memória em questão: uma perspectiva histórico-cultural. Educ. Soc., v.21, n.71, p.166-93, 2000. Disponível em: <http://www.scielo.br/pdf/es/ v21n71/a08v2171.pdf>. Acesso em: 7 jan. 2009.

Conhecimento e produção de sentidos na escola: a linguagem em foco. Cad. Cedes, n.35, p.41-9, 1995. 
VERAS, R.P. País jovem com cabelos brancos: a saúde do idoso no Brasil. Rio de Janeiro: Relume Dumará, 1995.

VIGOTSKI, L. Problemas del desarrollo de la psique. Madrid: Visor, 1995. (Obras Escogidas, v.3).

GAMBURGO, L.J.L.; MONTEIRO, M.I.B. Singularidades del envejecimiento: reflexiones a partir de conversaciones con un anciano institucionalizado. Interface - Comunic., Saúde, Educ., v.13, n.28, p.31-41, jan./mar. 2009.

Este artículo trata de algunas peculiaridades de la vida de un anciano que vive en una Institución de Larga Permanencia, entrevistado en el contexto de una investigación cuyo objetivo fue el lenguaje como práctica dialógica de ancianos con las capacidades comunicativas preservadas. La narración nos permitió conocer las condiciones de vida y algunas especificidades tales como: (1) la institucionalización precoz, (2) la interdependencia entre los motivos para el aislamiento voluntario y la situación de abandono, (3) la aparente impropriedad de utilizar la categoría "ancianos" para englobar sujetos con edades muy diversas. Se entrevistaron cinco mujeres y un hombre. Las entrevistas proporcionaron el examen de recuerdos, sentimientos, valores, relaciones interpersonales y del propio lenguaje. Esperamos ofrecer subsidios para una mirada a la counicación del anciado que la considera como sistema simbólico fundamental para la inserción social; mirada diversa de la que se centra en las alteraciones consideradas "típícas" de la vejez.

Palabras clave: Envejecimiento. Lenguaje. Institucionalización. 